\title{
AMAMENTAÇÃO: IMPACTO PROVOCADO NAS GESTANTES HIV POSITIVAS
}

\author{
BREASTFEEDING: THE MEANING FOR PREGNANT POSITIVE HIV
}

AMAMENTACIÓN: EL IMPACTO PARA LAS GESTANTES HIV POSITIVAS

\section{Dayane Cristina Silva Vinhas ${ }^{1}$ Leilinéia Pereira Ramos de Rezende ${ }^{2}$ Cleusa Alves Martins ${ }^{3}$ Jane Portes de Oliveira ${ }^{4}$ Rayssa Fátima Hubner-Campos ${ }^{4}$}

\begin{abstract}
RESUMO: Nas ações de prevenção ao HIVIAIDS, no pré-natal objetiva o aconselhamento de mulheres infectadas pelo HIV sobre o risco da transmissão vertical levando a proibição da lactação e da amamentação cruzada. Objetivos identificar junto as gestantes HIV positivas as principais preocupações quanto ao impedimento da amamentação natural e avaliar a necessidades de atividades educativas individuais como forma alternativa ao apoio psico-emocional e afetivo à gestante. Metodologia trata-se de uma abordagem qualitativa, foram entrevistadas gestantes soropositivas inscritas no ambulatório de pré-natal de alto risco, de um Hospital Público, em Goiânia-GO. Analisando os dados: as entrevistadas foram unânimes em afirmar que a gravidez não foi planejada. Estar grávidas e descobrir que são portadoras do vírus HIV trouxe maior expectativas em relação à gravidez: medo, insegurança, angústia e dúvidas são emoções por elas relatadas. E, ressaltaram que os grupos específicos permitem maior liberdade para discussão e troca de experiências, o trabalho ajuda a gestante reagir às conseqüências do vírus HIV. Assim sendo, entendemos que a assistência às grávidas soroposotivas, na instituição estudada atende um padrão de qualidade, entretanto, é importante sistematizar a formação de grupos específicos de grávidas soropositivas para HIV.
\end{abstract}

PALAVRAS CHAVE: Pré-natal de risco; Enfermagem; HIV.

ABSTRACT: In The actions of prevention to the HIV AIDS, in the prenatal lens the advising of women infected by the HIV about the risk from the vertical transmission causing to prohibition from the lactation and from the breastfeeding crossed. Objective it identify joined the pregnants HIV positive the main worries as regards the impediment from the breast-feeding natural and evaluate the individual educational needs of activities as form alternative to the affectionate and psychic emotional support to the pregnant. Methodology treats itself of a boarding qualitative, they were interviewed pregnants soropositivas inscription in the outpatient clinic of prenatal of high risk, of a Public Hospital, in Goiânia GO. Analyzing the facts: them interviewed were unanimous in affirm that to pregnancy was not planned. It be pregnant and uncover that they are bearers of the virus HIV brought bigger expectations regarding the pregnancy: fear, insecurity, anguish and doubts are emotions by them related. And, they stood out that the specific groups permit bigger liberty for argument and change of experiences, the work helps to pregnant react to the consequences of the virus HIV. Like this being, we understand that the aid to the pregnant soroposotive, in the institution studied attends a standard quality, however, is important thing systematize the specific formation of groups of pregnant soropositives for HIV.

KEY WORDS: Risk Prenatal; Nursing; HIV.

RESUMEN: En las acciones de la prevención al SIDA del HIV, en la lente prenatal el aconsejar de las mujeres infectadas por el HIV sobre el riesgo de la transmisión vertical que causa a la prohibición de la lactancia y del amamantamiento cruzado. El objetivo que identifica ensambló positivo del HIV para las mujeres embarazadas la cañería se preocupa en lo que concierne al impedimento del amamantamiento natural y evalúa las necesidades educativas individuales de actividades como alternativa de la forma a la ayuda emocional cariñosa y psíquica al embarazado. La metodología se trata de subir cualitativo, ellas era inscripción entrevistada con de los soro positivas de las mujeres embarazadas en la clínica del paciente no internado de prenatal del alto riesgo, de un hospital público, en Goiânia VA. Analizar los hechos: se entrevistaron con eran unánimes adentro afirman eso al embarazo no fueron planeados. Sea embarazado y destapa que son portadores del HIV del virus traído expectativas más grandes con respecto al embarazo: el miedo, la inseguridad, la angustia y las dudas son emociones al lado de ellas relacionadas. Y, estaban parada fuera de ésa la libertad más grande del permiso específico de los grupos para la discusión y el cambio de experiencias, las ayudas del trabajo a embarazado

\footnotetext{
${ }^{1}$ Acadêmica da Faculdade de Enfermagem da Universidade Federal de Goiás-FEN/UFG.

${ }^{2}$ Acadêmica da Faculdade de Enfermagem da Universidade Federal de Goiás-FEN/UFG

${ }^{3}$ Orientadora, Doutora e Professora Adjunta da Faculdade de Enfermagem da Universidade Federal de Goiás FEN/UFG

${ }^{4}$ Enfermeira Obstétra do Hospital Materno Infantil de Goiás.
} 
VINHAS, Dayane Cristina Silva; REZENDE, Leilinéia Pereira Ramos; MARTINS, Cleusa Alves; OLIVEIRA, 17 Jane Portes; HUBNER-CAMPOS, Rayssa Fátima - Amamentação: impacto provocado nas gestantes HIV positivas. Revista Eletrônica de Enfermagem, v. 06, n. 01, p.16-24, 2004. Disponível em www.fen.ufg.br

reacciona a las consecuencias del HIV. Como este ser, entendemos que la ayuda al soro positiva, en la institución estudiada atiende a un estándar de la calidad, sin embargo, está la cosa importante sistematiza la formación específica de los grupos de las embarazadas soro positivas embarazadas para el HIV.

PALABRAS CLAVE: Prenatal de riesgo; Enfermería; HIV

\section{INTRODUÇÃO}

O estudo foi realizado em duas instituições públicas que prestam atendimento à mulher no ciclo grávidopuerperal, são maternidades consideradas como centro de referência para alto risco, portanto, atendem gestantes e parturientes encaminhadas de vários municípios goianos e de outros Estados. Ainda, um deles possui um Banco de Leite que dá suporte aos recém-natos prematuros e de baixo peso dessa maternidade e também atende outras instituições, em Goiânia.

Em dezembro de 2000, esses hospitais receberam títulos honoríficos, por promoção e incentivo ao aleitamento materno e adequação das rotinas, práticas e treinamento da equipe envolvida na assistência à mulher no processo do parto e nascimento, de forma a atender os requisitos à adoção de medidas de promoção do sucesso do aleitamento materno. Em maio, de 1999, foi implantado o serviço de pré-natal de alto risco para assistir grávidas com diagnóstico de hipertensão arterial, diabetes mellitus, HIV positivas, deficiência física, mulheres com idade acima de 30 anos e adolescentes.

Somente como esclarecimento, uma das instituições desenvolve atividades que estimulam e incentivam o aleitamento natural. Mas, como Centro de Referência para gestantes de alto risco e soropositivas acata outras normas do Ministério da Saúde, onde existe um protocolo proibitivo ao aleitamento materno, na prevenção de infecção vertical.

A equipe multiprofissional - enfermeiro, assistente social, fonoaudiólogo, nutricionista e psicólogos realizam ações educativas, diariamente, com grupos de mulheres enquanto aguardam a consulta pré-natal. Nas reuniões, questões pertinentes à importância do pré-natal são abordadas, tais como os cuidados higiênico-dietéticos da gestante, livre demanda, alojamento conjunto, cuidados com recém-nascido, incentivo ao aleitamento materno, dentre outros.

As ações educativas no pré-natal, a princípio são realizadas com todas as gestantes que freqüentam 0 serviço. Contudo, a experiência tem mostrado a necessidade de ampliação do serviço, com inserção de profissionais do Centro de Orientação e Apoio Sorológico (COAS) na equipe de assistência às gestantes HIV soropositivas e sua família. A formação desse grupo é importante para abordagem de temas específicos - e discutir os riscos de transmissão do HIV, orientação quanto ao uso de medicamentos e impedimento à amamentação exclusiva, enfatizar a importância da participação da família evitar o constrangimento das gestantes e, oferecer um suporte emocional.

Segundo SERAFIN \& FILGUEIRAS (1999), para os coordenadores do Programa DSTs e AIDS, o aconselhamento coletivo oferece objetivamente aos usuários a oportunidade de redimensionar as dificuldades e compartilhar dúvidas, sentimentos e conhecimentos. A dinâmica grupal favorece ao indivíduo perceber sua própria demanda, reconhecer o que já conhece e sentir-se estimulado a participar dos atendimentos individuais subseqüentes. Para tanto, estabelecer estratégias adequadas de interação com a cliente para conquistar sua confiança, significa não submetê-las as nossas necessidades, conceitos e valores, mas também resulta em compreender que a mulher se encontra inserida em um contexto de natureza pessoal, social e cultural próprio, do qual os profissionais de saúde devem ter clareza ao assistir a clientela.

Há evidências de que a maioria da transmissão vertical ocorre mais tardiamente na gestação, durante o trabalho de parto e no parto. Conforme, já demonstrado em estudos 
multicêntricos realizados nos Estados Unidos e na França, as gestantes e mães que não amamentaram, apresentou redução na transmissão, aproximadamente de $70 \%$ com o uso do AZT na gestação, parto e no recémnascido.

No campo da prevenção o Ministério da Saúde registrou um dos maiores avanços com adoção do AZT na gestação e parto e, o esclarecimento a gestante quanto ao impedimento do aleitamento materno para se evitar a transmissão do vírus HIV pelo leite materno, como medida de controle e propagação.

Assim, na assistência à Saúde da Mulher é relevante o entendimento de que as ações de atenção à prevenção ao HIVIAids no pré-natal devam ser implementadas, visando o aconselhamento das mulheres infectadas pelo HIV sobre o risco de transmissão vertical levando a proibição da lactação, da amamentação cruzada. Em prematuros, inicialmente, recomenda-se 0 leite materno de bancos de leite credenciados pelo Ministério da Saúde, a seguir o leite artificial, conforme indicado.

NOVAK (2000) e FONSECA (1998) afirmam que mães HIV, não podem amamentar, pois existe o risco de aproximadamente $14 \%$ do bebê se contaminar com o leite materno, essa probabilidade aumenta quanto mais recente for a infecção. Contudo, se houver necessidade como fator de sobrevivência da criança, o leite pode ser ordenhado das mães e após pasteurização, oferecido ao recémnascido.

A amamentação, notadamente, é um momento importante na relação afetiva entre a mãe e a criança para se cultivar a intimidade, o carinho, a segurança do bebê, no entanto a mulher soropositiva impedida de amamentar deve estimular o carinho e a atenção ao seu filho.

Assim, durante nossa trajetória como enfermeiras, temos observado que a mulher soropositiva enfrenta uma série de desafios, como a possibilidade do bebê nascer contaminado. Também, há cobranças de outras mulheres internadas, amigos e familiares ao impedimento à amamentação do seu filho - você não vai amamentar o seu bebê? Ele está chorando de fome, dentre outras perguntas. Diante disso, surge um novo impasse, suportar as pressões sociais ou revelar o verdadeiro motivo que impede de amamentar o filho?

Nessa linha de entendimento, os enfermeiros ao prestarem assistência no enfoque preventivo devem atentar à necessidade de saúde cada gestante em aspectos relativos ao apoio emocional e psicológico que envolve a mulher no seu convívio social e familiar. No pensamento desse autor, os profissionais de enfermagem desfrutam de uma posição privilegiada, dentre outros profissionais, para educar as pessoas sobre as formas de reduzir o risco de transmissão do HIV. Os enfermeiros são percebidos como fontes confiáveis de informação sobre saúde e, comumente as pessoas se sentem bastante à vontade para discutir questões íntimas de sua pessoa.

O Ministério da Saúde (Brasil, MS, 2000a) afirma quando as pessoas vivenciam situações de ameaça a sua integridade física e emocional podem ficar fragilizadas e às vezes, não se sentem capazes de resolver solitariamente seus conflitos. E, ainda acrescentamos que, habilmente, os enfermeiros conseguem identificar o momento em que a cliente vive uma situação conflitante e estabelece prioridades na assistência de enfermagem.

$\mathrm{Na}$ prevenção não basta somente a informação, o profissional deve atuar em um trabalho de valorização da vida, ser agente transformador. Para tanto, deve-se utilizar uma abordagem que encontre ressonância nas reais condições da cliente e seja pautado na ética profissional da seriedade e respeito evitando situações de desconforto ou mesmo culpabilizá-lo pela doença, saber ouvi-la talvez seja uma postura prudente em alguns momentos.

Dessa forma, acreditamos que o estudo possa contribuir para a formação e aperfeiçoamento dos profissionais de saúde, no sentido de promover a humanização da assistência a gestante HIV positiva, e, como também refletir acerca as reuniões de prénatal realizadas por equipe multidisciplinar de 
modo sistemático de forma coerente com as necessidades e expectativas da clientela.

Com base no exposto, estabelecemos, como objeto de pesquisa, o estudo do modelo de assistência à gestante soropositiva para HIV, considerando o enfoque da humanização em ações educativas, no pré-natal de alto risco. Diante do exposto, definimos como objetivos: identificar junto as gestantes HIV positivas as principais preocupações quanto ao impedimento à amamentação; avaliar a necessidade de atividades educativas como forma de alternativas ao apoio psicoemocional e afetivo à gestante HIV positiva.

\section{ABORDAGEM METODOLÓGICA}

Considerando que o vírus HIVIAIDS se encontra amplamente inserido no cotidiano das mulheres e, gravemente atinge a gestante, dentre outros, como grupo de transmissão vertical, optamos por uma abordagem qualitativa, tipo estudo de caso, como forma de possibilitar uma compreensão mais abrangente dos fenômenos sóciopolíticos que envolvem assistência integral à saúde da mulher.

A pesquisa foi desenvolvida em um ambulatório de pré-natal de alto risco, de duas instituições hospitalares públicas, em Goiânia, no período de janeiro de 2001 a abril de 2003.

O grupo de sujeitos desta pesquisa foi composto pelas gestantes que concordaram em participar. Portanto, foram agendadas dezessete gestantes soropositivas para HIV, observando a Resolução 196/96 (Brasil, 1998) e após aprovação do Comitê de Ética da instituição onde a pesquisa foi desenvolvida. Desse modo, realizamos entrevistas gravadas (semi-estruturada) e, os depoimentos transcritos integralmente para análise, segundo as recomendações da análise de conteúdo.

\section{APRESENTAÇÃO E ANÁLISE DOS DADOS}

$\mathrm{Na}$ análise e discussão dos dados destacamos os pontos levantados em razão dos objetivos propostos, sem, contudo deixar de registrar aqueles depoimentos considerados importantes à compreensão mais ampla do contexto. Assim, elaboramos quatro categorias temáticas: caracterização da gestante HIV positiva; descobrindo ser gestante e portadora do vírus HIV; não amamentar: sonho ou realidade; pré-natal: o valor da orientação em grupo.

\section{Caracterização da gestante HIV positiva}

No sentido de delinear o perfil das gestantes optamos por dados como idade, grau de instrução, profissão, hábitos de vida, número de parceiros, religião e estado civil. Assim, idade das 18 entrevistadas variou dos 17 até os 39 anos. Entretanto, vale ressaltar que atualmente, vírus HIV se encontra em ascensão e nenhuma faixa etária deve ser excluída.

Neste estudo, identificamos que cinco gestantes cursaram o segundo grau, uma o curso ginasial, a maioria apenas o primário e uma referiu não ter estudo. Em relação às atividades profissionais, constatamos: uma cabeleireira, uma estudante, uma secretária, uma técnica em enfermagem, uma blocadora de gráfica, as demais do lar. No que diz respeito ao trabalho, a lei garante ao trabalhador o direito de não declarar ser portador de sorologia positiva.

Quanto ao estado civil das gestantes: a maioria era solteira, cinco casadas e três união estável. No que diz respeito ao número de parceiros com exceção de uma, as demais tiveram dois ou mais parceiros.

Hábitos de vida: todas depoentes informaram nunca ter sido usuária de drogas, oito referiu etilismo social e duas afirmaram serem tabagistas. O tabagismo tem sido associado a abortamentos, partos prematuros e recém-nascidos de baixo peso. Os recémnatos de mães alcoólatras podem apresentar a chamada síndrome alcoólica, que se manifesta por aspecto de debilidade mental e persiste após o nascimento. (NEME, 2000). Também, outros estudiosos referem que é discutível se o tabagismo e ingestão de bebidas alcoólicas são fatores capazes de acelerar a progressão para AIDS. Mas, sabese que o álcool aumenta a replicação dos 
níveis em linfócitos e assim tem diminuindo a capacidade de produzir interleucina.

Dentre os fatores de riscos associados ao crescimento intra-uterino retardado (CIUR) estão: abuso materno de drogas, fumo e álcool. Segundo conduta do Ministério da Saúde, os profissionais de saúde devem orientar as gestantes a evitar fumar e tomar bebidas alcoólicas, por prejudicar a saúde da mãe e do bebê. SOUZA (2000) refere que, este é o momento adequado para a mudança de alguns hábitos inadequados como, por exemplo, o tabagismo, o abuso de álcool e a falta de atividade física.

A religião predominante entre as entrevistadas foi a católica, uma espírita e outra não freqüenta nenhuma religião. Sabese que a religião pode ser um refúgio quando as pessoas apresentam doenças, socialmente estereotipadas consideradas graves ou incuráveis, pois, a preocupação com a iminência da morte, com a solidão e com a perda de controle pode dar origem a interesses espirituais e a busca de apoio religioso. TYMCHAK (2000) afirma, quando conseguimos conjugar a saúde física, com a vida espiritual rica podemos enfrentar as pressões, solucionar os problemas e conviver com os insolúveis com serenidade, coragem e otimismo até o dia determinado por Deus.

\section{Descobrindo ser gestante e portadora do vírus}

Como rotina de pré-natal é imprescindível, solicitar o exame para HIV fazendo o aconselhamento antes e após o teste, por um profissional na área de saúde competente. A maioria das entrevistadas afirmou que a gravidez não foi planejada e nem desejada, este dado revela que, em Goiás, a realidade é semelhante a outras regiões do país. Na maioria dos casos, a gravidez surge da falta de informação e precauções por parte do casal, muitas mulheres abandonam o uso de métodos contraceptivos por não estar com parceiros e ocasionalmente, mantém atividade sexual sem proteção.

Nessa linha de pensamento, compete aos enfermeiros identificar o momento apropriado e manter um canal aberto com a cliente para conversar acerca do exercício da sua sexualidade, 0 aconselhamento na escolha dos métodos anticoncepcionais, as implicações para o feto de uma relação sem preservativos e a responsabilidade principalmente, se o parceiro for soropositivo para HIV, aumentando a sobrecarga viral da mulher. Sobretudo, estimular a importância do relacionamento sexual e afetivo contribuindo na auto-estima e qualidade de vida.

$\mathrm{Na}$ assistência a mulher HIV soropositiva as orientações sobre o seu futuro reprodutivo deve atentar aos métodos de anticoncepção uma que a gravidez indesejada acarreta maiores problemas sociais e emocionais. O uso do preservativo feminino ou masculino, além de servir como método contraceptivo, previne a reinfestação do vírus HIV e as DSTs. Atualmente existe uma ampla tendência à discussão sobre a falta de adoção ou uso inadequado de métodos contraceptivos resultando em gravidez inesperada e ou indesejada, várias depoentes foram bastante enfáticas ao afirmarem não planejar nem desejar a gravidez. Outras disseram:

"Não planejei e não desejei esta gravidez, aconteceu assim a camisinha estourou".

"Não planejei não, não planejei e não foi desejada, foi uma coisa que veio, realmente veio, eu fui vítima de estupro. Levei pra frente".

Entretanto, houve aqueles casos em que a gravidez não foi planejada para aquele momento, mas, as mulheres disseram não ter sido uma gravidez desejada. Outros discursos revelam aceitação das gestantes. $\mathrm{Na}$ maioria das mulheres a descoberta da soropositividade do vírus da Aids gera conflitos significativos quanto aos riscos para o feto, conforme evidenciamos:

"A gravidez não foi planejada, mas agora é desejada. Eu acho que uma criança não é culpada dos seus erros, a única ansiedade é a criança nascer com 
o vírus, pois não foi uma gravidez planejada. Se fosse planejada eu acho que meu filho não correria este risco, eu e o pai faríamos o exame, se soubéssemos, jamais eu iria engravidar".

Cabe salientar que muitas mulheres só tomam conhecimento do diagnóstico do vírus da Aids quando estão grávidas ao realizarem os exames de pré-natal. Para ANDRIES (2000) são emoções contraditórias que se chocam tão violentamente neste momento, que a gestante pensa que não vai suportar. No entanto, passada a fase inicial, ela percebe que a vida pulsa em seu ventre é muito mais forte do que seu próprio medo e preconceito.

No que diz respeito à forma como as gestantes reagem ao descobrir serem portadoras do vírus HIV, os relatos das entrevistadas revelaram que elas sentem perdidas, inconformadas, indignadas e decepcionadas com a frieza de alguns profissionais de saúde ao informar o diagnóstico e encaminhá-las aos serviços especializados:

"Há um ano tomei conhecimento, após uma gravidez, o médico solicitou exame, eu fiz, ah! eu fiquei deslocada, chocada, não sabia como reagir à doença, cheguei ir ao médico e o médico já me encaminhou para o Materno, não questionou sobre o exame".

"Há dois meses, através do exame do meu filho que vai fazer dois anos, ele adoeceu e internou-se deu muito tipo de doença infecciosa: sapinho, diarréia crônica, eu levei ele em muitos médicos em Anápolis, desconfiaram porque não sarava, então conversaram comigo e pediu o exame, porque não sarava. Fiquei chocada, eu e meu marido e toda minha família não esperávamos. Não pediram o exame de HIV nesta gravidez, no pré-natal em Anápolis. Depois viemos para o Hospital e o médico pediu o exame meu e do meu esposo, chorei, chorei, precisou até da psicóloga conversar comigo".
Outros estudos também mostram que inicialmente, algumas pessoas reagem negativamente ao tomarem conhecimento da infecção ou da doença, talvez seja uma forma construtiva de enfrentar o choque do diagnóstico. A pessoa infectada pode ficar deprimida pela ausência de cura e ainda pela sensação de impotência resultante da perda de controle provocada pela necessidade de exames médicos mais freqüentes e diante da consciência de que o vírus tomou conta do corpo, são fatores importantes que devem ser considerados pela equipe de saúde (BRASIL, MS, 1999).

Portanto, na assistência pré-natal as reuniões devem ser realizadas por equipe multidisciplinar de modo sistemático com espaços para discussões onde as gestantes possam expressar claramente seus sentimentos e dúvidas acerca dessa problemática e, orientar quanto a perspectiva digna de qualidade de vida e saúde da mãe e feto.

No sentido de manter a vida sexual ativa, LAMBERT \& NOGUEIRA (1999) afirmam, dentre alguns procedimentos considerados adequados ao preservar a vida da mulher soropositiva HIV e evitar-se reinfestações virais recomenda-se, o uso de condon independente de estar grávida ou como prevenção de gravidez indesejada.

\section{Não Amamentar: Sonho ou Realidade?}

A sociedade em geral reconhece que amamentação natural é fundamental ao desenvolvimento e à saúde do bebê, promove o vínculo afetivo entre mãe e filho, dentre outras vantagens. Contudo, há situações de mulheres soropositivas para HIV, em que o aleitamento materno é contra indicado e, nesse caso é melhor que a mãe ofereça o leite artificial dando ao filho atenção e carinho, todavia deve-se tomar esse momento que á singular uma interação maternal cultivando uma relação de intimidade entre ambos, enquanto oferece a mamadeira.

Contudo, em alguns países onde a mortalidade infantil é alta por desnutrição e 
VINHAS, Dayane Cristina Silva; REZENDE, Leilinéia Pereira Ramos; MARTINS, Cleusa Alves; OLIVEIRA, 22 Jane Portes; HUBNER-CAMPOS, Rayssa Fátima - Amamentação: impacto provocado nas gestantes HIV positivas. Revista Eletrônica de Enfermagem, v. 06, n. 01, p.16-24, 2004. Disponível em www.fen.ufg.br

falta de saneamento, aconselha-se o leite materno de mães HIV positivo, pois o risco de morte para a criança é maior quando não amamentadas. Na África, algumas regiões são bastante precárias, o acesso á água potável e ao leite artificial é difícil e a amamentação é prática muito arraigada nessa população, assim o aleitamento natural tem sido uma situação rotineira entre essas mães. NEME (2000).

A maioria dos casos de transmissão vertical do HIV (65\%) ocorre na hora do parto, com a minoria dos casos representativos por transmissão placentária ou ainda um risco médio de $15 \%$ por aleitamento materno. Desse modo, formalmente está contra indicado a lactação por parte de mulheres HIV positivo (BRASIL, MS, 2001a).

Em Goiás, a rede pública de saúde adota conduta de não amamentar os recémnatos, conforme protocolo o Ministério da Saúde. Nesse sentido as gestantes são orientadas pelos profissionais de saúde, embora algumas gestantes se neguem a aceitar essa realidade, outras se mostram indiferentes, enquanto a maioria acata passivamente as orientações dos profissionais:

"Já amamentei, mais por incrível que pareça eu amamentei o meu primeiro filho até o quarto mês, e ele não pegou o vírus, graças a Deus. A assistente social me orientou depois que ganhei nenê".

"Pela amamentação e pelo parto também, o médico falou e eu participei de um grupo que também faz parte do pré-natal, aqui no materno e participei das palestras".

A amamentação dos recém-nascidos por mães portadoras do vírus HIV será sempre contra indicada tenham ou não recebido anti-toxinas. O aleitamento materno deixa de ser vantajoso e passa a representar riscos reais para o bebe. Por isso, as mães devem ser aconselhadas à supressão da lactação e substitui-la por outros leites. É importante que a puerpéra durante sua permanência na maternidade receba suporte por parte da equipe de saúde para não amamentar sem se sentir discriminada. (BRASIL, MS, 2001b).

\section{A Reação da Gestante HIV positiva em não poder amamentar}

Quanto ao conhecimento da transmissão do vírus da AIDS pelo leite materno e a contra-indicação da amamentação as gestantes responderam:

"Há! É como se estivesse tirando um pedaço de mim, sei lá, ter o leite e não poder dar o leitinho para meu nenê sabendo que tem leite e não pode dá". "Este é o segundo filho, eu não vou amamentar, pois agora com a experiência do primeiro filho sei o risco que corremos em amamentar é maior, e sei que será melhor pra ele".

Embora, a maioria de gestantes tenha preferido a informação sobre a impossibilidade do aleitamento natural, os depoimentos revelam o sofrimento e a grande tristeza de muitas mães em ter abdicar-se de dar o seio ao seu filho, pois amamentar o filho parece ser uma tarefa corriqueira para a maioria das mulheres. Entretanto, para esse grupo representa a falta de oportunidade de exercer a maternidade em sua integralidade. Entretanto, Segundo o Ministério da Saúde (BRASIL, MS, 1999) a história que cada grávida traz deve ser acolhida integralmente, pois os relatos e de seus acompanhantes são parte dos fatos, emoções ou sentimentos da gestante que podem ser claramente percebidos pelos membros da equipe.

\section{Pré-natal: o valor da orientação em grupo}

Quando as pessoas vivenciam situações de ameaça a sua integridade física ou emocional, costumam ficar fragilizadas e, às vezes, não se sentem capazes de resolver solitariamente seus conflitos. E, a disponibilidade mútua em trocar conhecimentos e sentimentos ajuda em muito a superar as ansiedades e a situação de conflitos. Nesse sentido, o pré-natal é um momento privilegiado para se discutir e esclarecer questões que são únicas para 
VINHAS, Dayane Cristina Silva; REZENDE, Leilinéia Pereira Ramos; MARTINS, Cleusa Alves; OLIVEIRA, 23 Jane Portes; HUBNER-CAMPOS, Rayssa Fátima - Amamentação: impacto provocado nas gestantes HIV positivas. Revista Eletrônica de Enfermagem, v. 06, n. 01, p.16-24, 2004. Disponível em www.fen.ufg.br

cada mulher e seu parceiro e apropriado para preparação ao parto e, possíveis intercorrências da gestação. (BRASIL, MS, 2000b)

As ações educativas no pré-natal em grupos de gestantes, no entendimento das entrevistadas as temáticas específicas devem ser abordadas em grupos. Embora seja fundamental reservar momentos individuais com as gestantes, como forma de confiança e interação cliente e profissional levando em conta as particularidades, as angustias, os conflitos, medos e dúvidas que provocam grande ansiedade nas grávidas ao conhecerem o risco de contaminação do filho. A maioria das depoentes referiu que teriam maior liberdade para discussão se houvesse momentos próprios desse grupo.

Nessa perspectiva, a opinião da maioria das gestantes foi favorável as reuniões apenas com grupo de gestantes HIV, houve depoimentos contundentes acerca da existência de preconceitos das pessoas quanto a AIDS. Aquelas que se manifestaram, contrariamente argumentaram a importância da orientação como forma de prevenção. Também, houve outras que sugeriram apenas acrescentar temas específicos para esse grupo.

"Acho melhor com grupo de gestante normal, não tenho preconceito poderia falar o que estou passando pra prevenir para outros não passarem o que estou passando".

"Bom poderia até todos juntos, mas né? tem muitas coisas que tem que ser discutidos, que poderia (...) tem alguns itens que poderia separar, ficaria melhor separar coisas que as mães pode fazer por seu filho e aquela que tem o vírus e tem outras que não podem então tem essa diferença. É porque ai no caso a gente ficaria sem jeito de perguntar né, às vezes de fazer perguntas. A gente está em dúvida, devido não ter aquele espaço para perguntas abertamente".

Para prevenir esse preconceito social, o Ministério do Trabalho tem ditado normas proibitivas de discriminação do trabalhador. Não há qualquer risco de se contrair o HIV nos contatos de convívio familiar, social ou profissional por isso, não deve existir o receio de conviver com alguém que tenha HIV ou AIDS. (BRASIL, MTE. 2000c).

\section{CONSIDERAÇÕES FINAIS}

O estar grávida e descobrir ser portadora do vírus HIV traz mudanças psicológicas profundas às mulheres, por conhecem que até $o$ momento a soropositividade HIV não tem cura, ocasionando maior expectativas em relação ao risco de contaminação fetal, medo, insegurança, angústia e dúvidas são emoções por elas relatadas. Assim, a formação de grupos específicos permite maior liberdade para discussão e troca de experiências. O trabalho ajuda a gestante reagir em relação às conseqüências nefastas do vírus HIV.

Observamos a importância do acompanhamento precoce ao pré-natal, pois a maioria das participantes foi unânime em afirmar que a gravidez não foi planejada e que só tomou conhecimento do seu diagnóstico após exames para HIV recomendado como rotina de pré-natal.

Em outra dimensão, é o momento importante na construção da cidadania da gestante soropositiva para HIV que significa exercer o direito a informações e acesso ao uso de anti-retrovirais na prevenção da transmissão vertical, medidas profiláticas como o uso de preservativos em todos as relações sexuais, evitando assim a reinfecção do vírus HIV, ou outros causadores de DSTs, e também evitar a gravidez indesejada. A educação em saúde é espaço que inclui a sensibilidade e os impactos vividos por cada mulher, buscar alternativas que visem a promoção e a mudança de hábitos, numa nova perspectiva com melhor qualidade de vida de nossos clientes.

O estudo objetivou mais do que realizar uma discussão sobre modelos considerados absolutos, refletir sobre as condições de assistência e, a necessidade de novas propostas. Consideramos que o profissional enfermeiro obstetra está apto a desempenhar com êxito a assistência ao pré-natal, em 
orientações individuais e/ou grupais. O apoio da equipe multidisciplinar propicia às pacientes um atendimento mais compatível e merecido com maior segurança e tranqüilidade.

Certamente, o enfermeiro numa proposta de construção em grupo, dentre outros objetivos, deve ter clareza e firmeza para imprimir atividades e estratégias que ao serem adotadas sejam capazes de dar respostas aos desafios contemporâneos de uma nova cultura, levando a mulher soropositiva a reflexão do seu mundo interior visando outras perspectivas além de saúde, mas assegurar seus direitos na sociedade como cidadã brasileira.

Por fim, ressaltamos que a assistência às grávidas soroposotivas, na instituição estudada atende um padrão de qualidade elevado com inclusão do aconselhamento em DST/Aids e estímulo ao exercício da sexualidade às mulheres com diagnóstico de soropositividade para HIV como fator relevante da saúde física e mental. Entretanto, é importante considerar a disposição dos membros da equipe de saúde no sentido de sistematizar a formação de grupos específicos de grávidas soropositivas para HIV, segundo manifestações e anseios da clientela.

\section{REFERÊNCIAS BIBLIOGRÁFICAS}

ANDRIES, S. Gravidez e Aids. Rio de Janeiro: Rev. Saber Viver. Ano 1, n. 5, jun./jul. 2000, 1-11 p.

BRASIL. Ministério da Saúde. Programa Nacional de DST/AIDS. Avaliação das Ações. Manual de Orientação Básica para equipe de enfermagem. Belo Horizonte: Ministério da Saúde. 1998, 217 p.

BRASIL, Ministério da Saúde. Coordenação Nacional de DST e AIDS.GONÇALVES. Aprendendo Sobre Aids e Doenças Sexualmente Transmissíveis: livro da família. Brasília: Ministério da Saúde. Coordenação Nacional de DST e AIDS.1999, p, 84.

BRASIL. Ministério da Saúde. Coordenação Nacional de DST e AIDS. Aconselhamento em DST, HIV e AIDS: diretrizes e procedimentos básicos. 4. ed. Brasília: Ministério da Saúde. Coordenação Nacional de DST e AIDS. 2000a, 25 p.

BRASIL. Ministério da Saúde. Área Técnica da Saúde da Mulher. Gestação de Alto Risco. Manual Técnico. 3. ed. Brasília: Ministério da Saúde. Secretaria de Políticas de Saúde. Área Técnica da Mulher. 2000b, 164 p.

BRASIL. Ministério do Trabalho e Emprego (MTE). O trabalhador e o HIVIAIDS. 2. ed. Revista Atual. Brasília: Assessoria Internacional. 2000c. 63 p.

BRASIL. Ministério da Saúde. Coordenação Nacional de DST e AIDS. Novo consenso sobre terapia anti-retroviral para adultos e adolescentes infectados pelo HIV. Brasília: Ministério da Saúde. Coordenação Nacional de DST/AIDS.2001a.

BRASIL. Ministério da Saúde. Área Técnica de Saúde da Mulher. Parto, Aborto e Puerpério: assistência humanizada a mulher. Brasília: Ministério da Saúde, Secretaria de Políticas de Saúde. Área Técnica da Mulher. 2001b, 199 p.: il.

FONSECA, E. M. A. M. Manejo e promoção do aleitamento materno. Goiânia: 1998, 18 p.

LAMBERT J. S. ;NOGUEIRA S. A. Manual clínico para o acompanhamento da gestante infectada pelo HIV. Rio de Janeiro: 3. ed. 1999, 86 p.

NEME, B. Obstetrícia Básica. 2.ed. São Paulo: Savier. 2000, 1362 p.

NOVAK, F. R. Dê ao bebê o melhor alimento. Revista Crescer-guia especial. São Paulo: Globo, 2000, 23 p.

SERAFIN, D.; FILGUEIRAS, S. L. Aconselhamento: um desafio para prática integral em saúde. Brasília: Ministério da Saúde, 1999, 69 p.

SOUZA, G. A. Pela manutenção da qualidade de vida da mulher. Jornal da SOBRAC. São Paulo: Ano VIII, n.3, 2000, p.15.

TYMCHAK, A. Enfrentando pressões. Rio de Janeiro: Revista Manancial.Ano 46, n. 3, jun/jul/ago/set 2000, $80 \mathrm{p}$.

Texto original recebido em 08/08/2003

Publicação aprovada em 30/04/2004 